\title{
Potestad jurisdiccional de la Corte Penal Internacional: el caso de Israel y Palestina, ¿estatolatría beligerante o falta de competencia?*
}

\author{
Jurisdictional Power of the International \\ Criminal Court: The case of Israel and Palestine, \\ ¿Belligerent Statolatry or Lack of Jurisdiction? \\ Poder jurisdicional do Tribunal Penal Internacional: \\ o caso de Israel e da Palestina, estatuto \\ beligerante ou falta de jurisdição?
}

Juan Carlos Caita-Moreno*

Fecha de recepción: 12 de febrero de 2021

Fecha de aprobación: 24 de junio de 2021

Doi: https://doi.org/10.12804/revistas.urosario.edu.co/anidip/a.10259

Para citar este artículo: Caita-Moreno, J. C. (2022). Potestad jurisdiccional de la Corte Penal Internacional: El caso de Israel y Palestina, ¿estatolatría beligerante o falta de competencia?, ANIDIP, 9, 1-23. Doi: https://doi.org//10.12804/revistas.urosario.edu.co/anidip/a.10259

\footnotetext{
* Este artículo participó en la Edición 2019 del Certamen de Ensayos Blattmann, Odio Benito y Steiner sobre Justicia Internacional Penal (СЕвоs).

** Abogado graduado con Honores por la Universidad Católica de Colombia, Especialista en Derecho Administrativo y Constitucional de la misma casa de estudios. Especialista en Justicia Constitucional y Derechos Humanos por la Università di Bologna (Italia). Máster (Cum Laude) di il livello in Scienze Politiche per la pace e l'Inteģrazione dei popoli por la Università deģli Studi di Salerno (Italia). Maģíster en Ciencia Política por la Universidad Católica de Colombia. Doctorando en Ciencias Jurídicas por la Pontificia Universidad Católica de Argentina. Actualmente se encuentra adelantando un Máster en Justicia Constitucional y Derechos Humanos en la Università di Bolognna (Italia), una Diplomatura en Derechos Humanos en la Universidad Austral (Argentina) y el Título de Experto en Aplicación del Derecho Internacional en Perspectiva Comparada en la Universidad de Mendoza (Arogentina) y la Universidad Autónoma de Madrid (España). Ha realizado cursos avanzados en Derechos Humanos, entre los que se destacan: Summer Courses Public International Law and Private International Law, The Hague Academy of International Law (Países Bajos). Correo electrónico: lacrimosajc@hotmail.com
} 


\title{
Resumen
}

En el año 2015, Palestina suscribió el Estatuto de Roma a pesar de la resistencia férrea y la presión en contrario ejercida por Israel y Estados Unidos, que puso en evidencia la ineficacia de la política exterior y la diplomacia norteamericana en Oriente Medio. Un año antes, en 2014, Palestina se convirtió en "Estado Parte" de la Convención de Viena de 1969 relativa al derecho de los tratados, posiblemente para anticiparse a Israel en la defensa de sus derechos como Estado desde 1948. Una de las principales consecuencias de la pertenencia de Palestina al Estatuto de Roma es, sin duda alguna, la jurisdicción automática de la Corte Penal Internacional (CPI) frente a eventuales crímenes internacionales perpetrados en los territorios controlados por la Autoridad Nacional Palestina (ANP). Frente a estos hechos, se plantearon los siguientes interrogantes: ¿qué consecuencias tiene para Israel el hecho de que Palestina sea el Estado miembro 123 en reconocer la jurisdicción de la CPI? Acaso, ¿no fueron los mismos principios de Núremberg los que inspiraron los juicios contra los criminales nazis que exterminaron el pueblo judío? Como Estado Parte del Estatuto de Roma, ¿logrará Palestina trasladar su histórico conflicto con Israel a La Haya? Y, a su vez, ¿la presión internacional obligará a Israel a ratificar el Estatuto de Roma?

Palabras claves: Estatuto de Roma; Israel y Palestina; derecho penal internacional; competencia de la Corte Penal Internacional de La Haya; crímenes de guerra; crímenes internacionales.

\begin{abstract}
In 2015, Palestine signed the Rome Statute, despite the fierce resistance and pressure against it from Israel and the United States, highlighting the ineffectiveness of the latter's foreign policy and diplomacy in the Middle East. A year earlier, in 2014, Palestine became a "State Party" to the 1969 Vienna Convention on the Law of Treaties, possibly to pre-empt Israel in upholding its rights as a State since 1948. One of the main consequences of the Palestinian membership to the Rome Statute is undoubtedly the automatic jurisdiction of the International Criminal Court (ICC) over possible international crimes perpetrated in the Palestinian Authority controlled territories. In view of the previous facts, the following questions arise: What are the consequences of Palestine becoming the $123^{\text {rd }}$ member State to recognize the jurisdiction of the ICC for Israel? Wasn't it the same Nuremberg principles that inspired the trials of the Nazi criminals who exterminated the
\end{abstract}


Jewish people? As a "State Party" to the Rome Statute, will Palestine succeed in transferring its historic conflict against Israel to The Hague? And, for that matter, will the international pressure force Israel to ratify the Rome Statute?

Key words: Rome Statute; Israel and Palestine; international criminal law; jurisdiction of the International Criminal Court in The Hague; war crimes; international crimes.

\section{Resumo}

Em 2015, a Palestina assinou o Estatuto de Roma, apesar da forte resistência e pressão contrária exercida por Israel e pelos Estados Unidos, destacando a ineficácia da política externa e da diplomacia norte-americana no Oriente Médio. Um ano antes, em 2014, a Palestina se tornou um "Estado Parte" da Convenção de Viena de 1969 sobre a lei dos tratados, possivelmente para antecipar a Israel na defesa de seus direitos como Estado desde 1948. Uma das principais consequências da adesão da Palestina ao Estatuto de Roma é, sem dúvida, a jurisdição automática do Tribunal Penal Internacional (TPI) em face de eventuais crimes internacionais perpetrados nos territórios controlados pela Autoridade Nacional Palestina. Diante desses fatos, surgem as seguintes questões: Quais são as consequências para Israel o fato de a Palestina ser o 123 estado membro a reconhecer a jurisdição do TPI? Talvez, não foram os mesmos princípios de Nuremberg que inspiraram os julgamentos contra os criminosos nazistas que exterminaram o povo judeu? Como Estado Parte do Estatuto de Roma, a Palestina conseguirá transferir seu conflito histórico com Israel para Haia? E, por sua vez, a pressão internacional forçará Israel a ratificar o Estatuto de Roma?

Palavras-chave: Estatuto de Roma; Israel e Palestina; Direito Penal Internacional;

Jurisdição do Tribunal Penal Internacional de Haia; Crimes de Guerra; Crimes

Internacionais. 


\section{Introducción}

La Corte Penal Internacional (CPI) es un tribunal permanente y estable. Es, en esencia, la primera jurisdicción internacional con misión y aspiración de universalidad y tiene la facultad de enjuiciar a personas físicas y, en circunstancias particulares, eliminar la responsabilidad penal internacional individual por los crímenes con mayor gravedad y trascendencia en la comunidad internacional. Según lo estipulado en el artículo 5 de su Estatuto, la CPI está facultada para juzgar crímenes de guerra, genocidio, crímenes de lesa humanidad y crímenes de agresión (Estatuto de Roma, 1998).

En el año 2015, Palestina suscribió el Estatuto de Roma. ${ }^{1}$ Una de las principales consecuencias de la pertenencia de Palestina a este es, sin duda alguna, la jurisdicción automática de la CPI frente a posibles crímenes internacionales perpetrados en los territorios controlados por la Autoridad Nacional Palestina (ANP), a propósito de las más recientes incursiones del ejército de Israel en la Franja de Gaza y Cisjordania. ${ }^{2}$

Frente a este hecho, Israel ha mostrado una cierta preocupación, aunque posiblemente no tenga la intención de cooperar con las investigaciones que eventualmente puedan adelantar los fiscales de la CPI, dada su nefasta experiencia con las resoluciones del Consejo de Seguridad de las Naciones Unidas que le han condenado en varias ocasiones por su política de construcción de asentamientos en territorios declarados como ocupados (Consejo de Seguridad, 2016).

La postura de Israel en este sentido podría girar en torno al alegato de falta de competencia de la CPI a la hora de investigar a sus soldados y agentes estatales, dado que Israel no es miembro del Estatuto de Roma. Además, dichas acciones pueden interpretarse como una agresión contra Israel, agravando las relaciones con la ANP y agudizando aún más el conflicto sin contar con el malestar que esto generaría en el coloso del norte que, a propósito, tampoco ha ratificado el Estatuto de Roma.

$1 \quad$ Estatuto de Roma de la Corte Penal Internacional de julio de 1998, enmendado por los procès-verbaux de 10 de noviembre de 1998; 12 de julio de 1999; 8 de mayo de 2000; 17 de enero de 2001 y 16 de enero de 2002. Fecha de entrada en vigor: 1 ㅇ de julio de 2002, Documento A/CONF. 183/9.

2

En su informe a la Asamblea General en 1947, el Comité Especial de las Naciones Unidas sobre la Cuestión de Palestina (unscop) recomendó que los países árabes incluyeran "Galilea occidental, Samaria y las montañas judías, excluyendo la ciudad de Jerusalén y la llanura costera de Estudiar a la frontera eģipcia". Pero la división del territorio fue determinada por la línea del armisticio en 1949, que se estableció después de la fundación de Israel y la primera guerra árabe-israelí. Los dos territorios palestinos son Cisjordania (incluida Jerusalén Oriental) y la Franja de Gaza, que están aproximadamente a 45 kilómetros de distancia. Sus áreas son 5970 kilómetros cuadrados y 365 kilómetros cuadrados, respectivamente. Cisjordania se encuentra entre Jerusalén, que tanto palestinos como israelíes afirman es su capital, y Jordania en el este, mientras que Gaza es una franja de 41 kilómetros de larogo y 6.12 kilómetros de ancho. Gaza tiene una frontera de 51 kilómetros con Israel, una frontera de 7 kilómetros con Eớipto y una costa de 40 kilómetros a lo larơo del Mar Mediterráneo. 
Por lo expuesto, consideramos que el gran reto que se le plantea a la CPI es el de enfrentar una disyuntiva importante: lograr que la investigación adelantada por los fiscales sea integral e imparcial, para garantizar que los enjuiciados sean de ambas partes, esto es, israelíes y palestinos que hayan cometido crímenes internacionales, dado que ocuparse únicamente de Israel enviaría un mensaje de persecución polarizada, y lograr una investigación autónoma e independiente a pesar de la contraposición política que sugiere desafiar a Estados Unidos.

Así pues, debemos analizar ciertos argumentos esgrimidos por Estados Unidos ${ }^{3}$ según los cuales Palestina no tiene calidad plena como Estado, por lo que estaría impedida para suscribir tratados internacionales, particularmente el que le permite pertenecer a la CPI, no obstante haber sido reconocida en 2012 como "Estado Observador No Miembro" por parte de la Asamblea General de las Naciones Unidas. Esta circunstancia lo faculta plenamente para celebrar tratados y otros instrumentos internacionales. Así como a analizar la vehemente reacción de Israel ante el más reciente anuncio hecho por la fiscal de la CPI, Fatou Bensouda, referente a la apertura de una investigación en los territorios controlados por Palestina, esto es, Cisjordania, Jerusalén Oriental y la Franja de Gaza (Oficina del Fiscal, 2019). Luego de haber realizado un examen preliminar en 2015, la fiscalía estimó que los jueces de la CPI deberían arrogarse la competencia para conocer acerca de presuntos crímenes de guerra cometidos por Israel en el marco de la denominada "marcha del retorno"4 de 2018 y otros enfrentamientos entre árabes e israelíes, tras lo cual el Primer Ministro Benjamín Netanyahu expresó que la jurisdicción de la CPI no es aplicable a los territorios ocupados, dado que aún se cuestiona la existencia de Palestina como Estado soberano (CNN en español, 2015).

Se toman en cuenta, por ejemplo, las expresiones del consejero de Seguridad Nacional de la Casa Blanca, John Bolton, quien ha resucitado argumentos del 2002 - primer mandato del presidente Georoge W. Bush, momento en que Estados Unidos no ratificó el Estatuto de Roma que en ese año creó la CPI- expresando que el Tribunal de La Haya es "superfluo" y "viola la soberanía nacional de los EE. UU.". Además, declaró que la indefinición de los delitos que persiguen los "burócratas de La Haya" puede constituir un pretexto para investigaciones con motivaciones políticas. A lo que ağregó: “¿Entreģarían ustedes el destino de los ciudadanos estadounidenses a un comité de otras naciones, incluidas Venezuela y la República Democrática del Conģo, o a entidades que ni siquiera son Estados, como la Autoridad Palestina?" (Guimón, 2018).

$4 \quad$ La denominada "Marcha del Retorno", producida más recientemente en el año 2018, fue iniciada por los palestinos - en sus palabras - para llamar la atención respecto a la lucha de cientos de miles de ellos que han sido expulsados de sus hogares en lo que hoy es Israel. Para Israel, fue una peligrosa provocación que puso en rieş̧o muchas vidas. La manifestación inició el 30 de marzo de ese año, es decir, en el "día de la Tierra", en el que los palestinos conmemoran la muerte de seis manifestantes en manos de las fuerzas de seģuridad israelíes durante las protestas que se llevaron a cabo ese mismo día en 1976 por la confiscación de sus tierras. La marcha duró hasta diciembre de 2018 y dejó, según la onu, 189 muertos y 6100 heridos, entre ellos niños, periodistas y personal de salud. 
Además de los argumentos esbozados por el primer ministro israelí, el fiscal general Avijai Mandelblit también cuestionó la decisión de la fiscal Bensouda, en tanto Israel no es parte de la CPI y cualquier solución a la disputa territorial considera que debería hacerse por la vía de la negociación bilateral entre ambas partes (Y net español, 2019; La Vanguardia, 2019).

Una comisión independiente del Consejo de Derechos Humanos (CDH) de las Naciones Unidas investigó los sucesos y aseguró tener motivos razonables para creer que los soldados israelíes cometieron violaciones del derecho internacional humanitario y de los derechos humanos. La Oficina del Alto Comisionado para los Derechos Humanos de las Naciones Unidas publicó el Informe de la Comisión mencionada anteriormente el 25 de febrero de 2019, que fue debatido en el cuadragésimo periodo de sesiones del CDH (Human Rights Council, 2019). En el citado informe, el CDH consideró que había motivos razonables para creer que los soldados israelíes habían violado el derecho internacional humanitario y las normas de derechos humanos durante las manifestaciones de la gran Marcha del Retorno. En las conclusiones del documento se destaca fundamentalmente: el pleno derecho de la población palestina a la libertad de expresión y manifestación, no teniendo Israel derecho a atacar niños, niñas, mujeres, paramédicos, periodistas, discapacitados ni minusválidos; que Israel cometió lo que puede equivaler a crímenes de guerra y crímenes de lesa humanidad; que las manifestaciones fueron totalmente pacíficas, y se pide, además, a los Altos Comisionados que remitan el caso a la CPI, ya que consideraron que las investigaciones israelíes no fueron serias. Finalmente, el reporte fue aprobado por el Consejo de Derechos Humanos de la oNU con veintitrés votos a favor.

\section{La cuestión de la autodeterminación}

La libre determinación es uno de los derechos más relevantes y significativos que le corresponden a todo pueblo. ${ }^{5}$ La Resolución 1514 (XV) de la Asamblea General de 1960, como los pactos internacionales de derechos humanos, estableció que "todos los pueblos tienen el derecho de libre determinación". En virtud de este derecho, y conforme a la citada resolución, los pueblos determinan libremente su condición política y persiguen libremente su desarrollo económico,

5 La CIJ, en su opinión consultiva sobre el Sáhara Occidental, afirmó que este es un derecho colectivo cuya titularidad corresponde a los pueblos. En esa oportunidad, la cIJ expresó con suma claridad que el derecho a la autodeterminación corresponde a las "poblaciones". En consecuencia, no corresponde ese derecho a los dirigentes o gobernantes, sino propiamente a sus poblaciones, esto es, al conjunto de sus habitantes origginarios. Solo el conjunto de estos individuos, y no una parte de estos, es titular del derecho y puede disponer de este (CIJ, 1975). 
social y cultural. Además, según se establece en su sexto párrafo: "todo intento encaminado a quebrar total o parcialmente la unidad nacional y la integridad territorial de un país es incompatible con los propósitos y principios de la Carta de las Naciones Unidas".

Una década después, en una etapa superior de evolución de este principio, la Resolución 2625 (XXV), reguladora de los principios de amistad y cooperación entre los pueblos, afirmó el derecho a la autodeterminación de los pueblos y el deber de todos los Estados de respetar dicho derecho. Dicho deber incluye la obligación de abstenerse de todo recurso a la fuerza tendiente a privar a los pueblos del ejercicio de su derecho de autodeterminación. Consecuentemente, los pueblos que encuentren resistencias por parte de terceros al ejercicio de este derecho podrán pedir y recibir apoyo de conformidad con los principios de la Carta de las Naciones Unidas. Esta resolución consagra, además, el "principio de la no intervención” y el "principio de cooperación pacífica entre los Estados".

En el conflicto bajo análisis, cualquier posición internacional o proceso de negociación que se haya puesto en marcha en el mismo ha partido siempre de la afirmación de que el pueblo palestino es un "pueblo" en el sentido que le otorga el ordenamiento jurídico internacional y, como tal, tiene o goza del derecho a su libre autodeterminación. En relación con este punto, la afirmación de la subjetividad internacional y el ejercicio del derecho a la autodeterminación del pueblo palestino van de la mano, dado que lo que realmente define la existencia de un pueblo es la titularidad de derechos y obligaciones internacionales, así lo dispuso la CIJ en su opinión consultiva del 9 de julio de 2004. En igual sentido, lo han reconocido en múltiples resoluciones la Asamblea General de la ONU (1971;1974), así como otros organismos de esta. Esto, a su vez, ha sido expresado reiteradamente por la gran mayoría de Estados que conforman la comunidad internacional. La última resolución aprobada por el Consejo de Derechos Humanos de la Asamblea General de la ONU en marzo de 2019, con 41 votos a favor, 3 en contra y 2 abstenciones expresa principalmente que se afirma el derecho del pueblo palestino a la libre determinación y deplora la situación de millones de refugiados y desplazados palestinos que han sido desarraigados de sus hogares. Afirma además la aplicabilidad del principio de soberanía permanente sobre los recursos naturales a la situación palestina como componente integral del derecho a la libre determinación y considera que este derecho sigue siendo vulnerado por Israel con la existencia y continua expansión de los asentamientos en el territorio palestino ocupado por lo que exhorta a Israel, potencia ocupante, a poner fin de inmediato a dicha ocupación del territorio palestino, incluida Jerusalén Oriental. 
Tal como ya se ha señalado en este trabajo, recientemente se ha manifestado públicamente la decisión de la CPI de indagar respecto de los crímenes denunciados por el gobierno palestino ante esta. La fiscal del caso, Fatou Bensouda, ha dictaminado que existen suficientes motivos para investigar a todas las partes con respecto a los crímenes de guerra cometidos durante la "Operación Margen Protector", al "crimen de los asentamientos" y los incidentes de disparos a lo largo de la valla de Gaza.

No obstante, a inicios del 2021, la fiscal Bensouda debió esperar la confirmación de si la CPI tiene jurisdicción sobre el caso y, además, cuál sería el alcance de dicha jurisdicción bajo el Estatuto de Roma. Por lo que en marzo pasado, la CPI anunció la apertura de una investigación sobre "crímenes de guerra" cometidos en los territorios palestinos ocupados.

Por su parte, la posición legal del Estado de Israel, conforme la respuesta dada a través del fiscal general es, en primer lugar, que este no es parte de la CPI, por lo tanto, esta no tiene jurisdicción en relación con Israel, y, en segundo lugar, cualquier acción palestina con respecto a la CPI es inválida, ya que solo los "Estados soberanos" pueden delegar su jurisdicción penal en ella. Para Israel, la ANP claramente no cumple con el criterio de un Estado bajo el derecho internacional ni el Estatuto de Roma (Vacas Fernández, 2015).

Comenzaremos a analizar el segundo argumento dado por Israel, con el objetivo de llegar a esta instancia con una mejor evaluación de la situación desde un punto de vista tanto político como jurídico. Para ello, recordemos que Palestina aceptó la competencia de la CPI en enero de 2009 con respecto a los crímenes cometidos en su territorio desde el primero de julio de $2002 .{ }^{6}$ No obstante, ese reconocimiento de jurisdicción no surtió los efectos pretendidos. ${ }^{7}$ Esto determinó el inicio de un

Tal como ya hemos analizado en este trabajo, el 21 de enero de 2009, la ANP emitió una declaración reconociendo la jurisdicción de la CPI de conformidad con el artículo 12, párrafo 3 del Estatuto de Roma, por una duración indeterminada cuyos efectos se fijaban a partir del primero de julio de 2002. Posibilidad prevista en el artículo mencionado, por consiguiente, cualquier Estado que no sea parte en el Estatuto de Roma podrá reconocer la jurisdicción de la CPI, sin que se establezca ningún límite temporal para el reconocimiento de dicha jurisdicción, por lo que quedará a la voluntad del Estado que en ejercicio de su soberanía realice tal reconocimiento el establecer desde cuándo surtirá efectos, con el límite general a la competencia temporal de la CPI, que deriva del principio de irretroactividad penal, que se establece en el artículo 11. 1. de su Estatuto: "La Corte tendrá competencia únicamente respecto de crímenes cometidos después de la entrada en vigor del presente Estatuto".

7 La anP no tenía reconocido, como hemos visto, el estatus de "Estado" ni por la Asamblea General de la ONu ni por la Asamblea de los Estados Parte del Estatuto de Roma. En consecuencia, la declaración de 2009, al haber sido emitida por una entidad no estatal carecía de validez en los términos requeridos por el artículo 12. 3. del Estatuto de Roma. La ausencia de validez de oriģen, sostiene Vacas Fernández (2015), que no se ha visto afectada por el posterior cambio de Estado de Palestina ante la onu a raíz de la aprobación de la Resolución 67/19 de la Asamblea General de 29 de noviembre de 2012, por la que pasó a ser "Estado Observador No Miembro", ya que carece de efectos retroactivos. 
proceso de acercamiento de Palestina a la CPI, que tuvo su continuación casi seis años después, el 31 de diciembre de 2014, con una nueva declaración de reconocimiento de su jurisdicción por parte del "Estado de Palestina", esta vez desde la perspectiva de la onU. Este acercamiento culminó el 2 enero de 2015, con el depósito de los instrumentos de adhesión al Estatuto de Roma y al Acuerdo sobre Privilegios e Inmunidades de la Corte (onu, 2002) que marcó el inicio de una nueva etapa en esta relación (Vacas Fernández, 2015).

Desde el punto de vista jurídico, la condición de Palestina como Estado resulta, sin duda, esencial. El Estatuto de Roma exige, tanto en su artículo 12. 3. - en relación con la declaración de aceptación de la jurisdicción de la Corte-, como en el artículo 125. 3. - por lo que a la adhesión al Estatuto mismo se refiere-, que una y otra sean realizadas por un Estado.

El reconocimiento de Palestina como Estado, tal como hemos podido apreciar, no se limita al último lustro, más bien, se remonta a décadas atrás, siendo hoy reconocida por 135 países de los 193 que conforman la comunidad internacional institucionalizada. Dicho reconocimiento, aunque relevante, no resulta decisivo por la naturaleza discrecional, política y no constitutiva del mismo. No obstante, uno de los elementos para rechazar la estatalidad de Palestina fue precisamente que no había sido reconocida como un Estado por instituciones internacionales claves, siendo esta - se sostenía - una indicación adicional de que la comunidad internacional no reconoce a Palestina como Estado (Ash, 2009). Concretamente, lo que permitió el cambio de estatus reconocido por la comunidad internacional fue la aprobación de la Resolución 67/19 de noviembre de 2012.

Sin perjuicio de los derechos ya adquiridos por la Organización para la Liberación de Palestina (OLP), Palestina en las Naciones Unidas pasó de ser entidad no miembro a Estado no miembro. Cabe resaltar que la resolución fue aprobada por el grueso de la Asamblea, a pesar de haber sido radicalmente rechazada por Israel, protagonista en el conflicto árabe-israelí. A partir de esa fecha, el reconocimiento de Palestina como Estado es incuestionable y le abrió la posibilidad de otorgar su consentimiento para obligarse en virtud de tratados internacionales multilaterales amplios, como lo hizo al ser reconocido como miembro de pleno derecho de la Unesco y otros tratados en materia de derechos humanos y de derecho internacional humanitario.

Por lo anterior, cabe ahora analizar el tema de la jurisdicción de la CPI. Para ello, desde una perspectiva jurídica, es necesario apelar a las normas vigentes que surgen principalmente del Estatuto de Roma, aclarando que, en relación con los exámenes preliminares, el procedimiento aplicado por la Fiscalía está determinado por el Documento de política general sobre exámenes preliminares (CPI, 2019). 
Para comenzar, es imperioso abordar la cuestión de la competencia personal, temporal y material de la CPI en relación con el caso que nos ocupa, estableciendo los parámetros generales y particulares a partir de los cuales la CPI posee competencia en este caso y en virtud del cual desplegará toda su actividad, primero, a través de la Fiscalía, en relación con el examen preliminar y, eventualmente, con la apertura de una investigación al respecto que conduzca al resultado final -el procesamiento, en su caso, de determinadas personas-.

Sostiene Olásolo Alonso (2009), en este sentido, que los Estados parte han atribuido a la CPI el poder para investigar, enjuiciar, declarar y realizar la responsabilidad penal individual derivada del Estatuto de Roma, lo que conforma la llamada "dimensión penal de la potestad jurisdiccional de la Corte" en un "Estado latente", refiriéndose el citado autor a este fenómeno con la expresión "jurisdicción abstracta de la Corte". Pero al mismo tiempo, los Estados Parte han establecido los siguientes presupuestos para la activación de esta dimensión penal de la potestad jurisdiccional con respecto a una determinada situación de crisis: a) la inclusión de los parámetros personales, temporales y territoriales que definen la situación de que se trate dentro del ámbito personal, temporal y territorial de la jurisdicción abstracta de la CPI; b) la existencia de un fundamento razonable para creer que en la situación de que se trate se han cometido delitos previstos en el Estatuto de Roma; c) la inacción, la falta de disposición o la incapacidad de las jurisdicciones nacionales para investigar y enjuiciar los delitos presuntamente cometidos en situación de que se trate (admisibilidad de la situación); d) la ausencia de una solicitud del Consejo de Seguridad, conforme al artículo 16 del Estatuto de Roma, para que la jurisdicción abstracta de la CPI no sea activada con respecto a la situación de que se trate; e) la suficiente gravedad de los delitos presuntamente cometidos en la situación de que se trate, y f) la inexistencia de motivos substanciales para creer que, a pesar de la gravedad de los delitos y de los intereses de las víctimas, la activación de la jurisdicción abstracta de la CPI sobre la situación de que se trate no redundaría en interés de la justicia. A lo que Olásolo Alonso (2009) agrega:

Solo una vez que la jurisdicción abstracta de la Corte haya sido activada con respecto a una determinada situación mediante la decisión de iniciar, o de autorizar su investigación, la Corte podrá ejercitar su poder para investigar, enjuiciar, declarar y realizar la responsabilidad penal individual que, conforme al Estatuto, haya surgido dentro de los parámetros personales, territoriales y temporales que definan dicha situación (p. 35). 
La dimensión de la activación de la potestad jurisdiccional de la CPI puede ejercerse de este modo, a instancia de un Estado Parte o del Consejo de Seguridad como consecuencia de la remisión de una situación o a solicitud de la Fiscalía tras la recepción por esta última de una denuncia. Además, los artículos 15, 18 y 53 del Estatuto de Roma establecen un conjunto ordenado de actuaciones a través de las cuales la CPI ejerce su poder para declarar la concurrencia o no de los presupuestos de activación para, en su caso, activar su jurisdicción abstracta sobre la situación de que se trate. Luego la Fiscalía, bajo la supervisión de la Sala de Cuestiones Preliminares (SCP), llevará a cabo la investigación de los delitos previstos en el citado estatuto que se hayan podido cometer en la situación concreta. En esta fase de investigación, que sigue al proceso de activación y precede al proceso penal propiamente dicho, que tiene una naturaleza "preprocesal" en palabras de Olásolo Alonso (2009), la Fiscalía es el órgano responsable de la práctica de aquellas diligencias de investigación que sean necesarias para el descubrimiento de los delitos y la identificación de los presuntos responsables.

Tal como hemos enunciado, el alcance de la potestad jurisdiccional de la CPI está definido por sus ámbitos material, personal, temporal y territorial. De acuerdo con su ámbito material, la jurisdicción abstracta de la CPI se extiende al delito de genocidio, los crímenes contra la humanidad, los crímenes de guerra y los delitos contra la administración de justicia de la CPI. Por su parte, el artículo 5 (1) del Estatuto de Roma incluye también el "delito de agresión".

Desde el punto de vista de la competencia personal, queda establecido en el propio estatuto que la competencia de la CPI es en general sobre las personas físicas, sin que su cargo suponga una limitación a ellas. El único límite viene establecido por el artículo 26 del Estatuto de Roma, que excluye de modo general la competencia de la CPI sobre los que fueren menores de dieciocho años en el momento de la presunta comisión del crimen. Aquí es importante tener en cuenta que tanto la Fiscalía de la CPI, como la Sala de Cuestiones Preliminares han señalado repetidamente que la CPI solo va a ejercer su jurisdicción personal en relación con aquellos líderes políticos y militares que tengan mayor responsabilidad por las campañas de delitos previstos en el Estatuto de Roma, presuntamente cometidos en las situaciones de crisis objeto de investigación (Olásolo Alonso, 2009).

En relación con la competencia temporal, el 2 de enero de 2015, Palestina depositó su instrumento de adhesión al Estatuto de Roma. Conforme a lo establecido en el artículo 126. 2. de dicho estatuto, el mismo ha entrado en vigor para Palestina el primero de abril de 2015. Esto tiene relevancia a fin de determinar la competencia de la CPI rationae temporis de acuerdo con el principio de irretroactividad penal 
consagrado en el artículo 11. $2{ }^{8}$ del Estatuto de Roma. Por lo tanto, en principio, será esa fecha a partir de la cual la CPI será competente. No obstante, es importante señalar en este punto que la competencia temporal de la CPI en este caso se ve ampliada en casi un año por efecto de la Declaración de aceptación de la jurisdicción de 31 de diciembre de 2014. Mientras la entrada en vigor del estatuto viene regulada por su artículo 126. 2, de acuerdo con la excepción establecida en el artículo 11. 2. in fine, en el caso de una declaración del artículo 12. 3, el Estado tiene libertad para determinar el momento a partir del cual consiente "que la Corte ejerza su competencia respecto del crimen de que se trate" — con el único límite general de la propia entrada en vigor del Estatuto-. Esto es lo que hizo Palestina, indicando expresamente en su declaración la fecha del 13 de junio de 2014 como el momento a partir del cual reconoce la jurisdicción de la CPI, que coincide con el inicio de la última operación militar de Israel en la Franja de Gaza denominada "Margen Protector" por Israel, que va a resultar decisiva en relación con la competencia material de la CPI, acaecida entre el 8 de julio y el 26 de agosto de 2014 .

La Corte afirmó que

entre las resoluciones redactadas de manera similar, la Asamblea General de las Naciones Unidas en la Resolución 67/19 [reafirmó] el derecho del pueblo palestino a la autodeterminación y a la independencia en su Estado de Palestina en el territorio palestino ocupado desde 1967.

Por lo cual, la mayoría, conformada por el magistrado Marc Perrin de Brichambaut y por la magistrada Reine Adélaïde Sophie Alapini-Gansou concluyeron que la jurisdicción territorial de la CPI en la situación en Palestina se extiende a los territorios ocupados por Israel desde 1967: Gaza, Cisjordania y Jerusalén Oriental.

$8 \quad$ Estatuto de Roma, artículo 11. 2: "Si un Estado se hace Parte en el presente Estatuto después de su entrada en vigor, la Corte podrá ejercer su competencia únicamente con respecto a los crímenes cometidos después de la entrada en viģor del presente Estatuto respecto de ese Estado, a menos que éste haya hecho una declaración de conformidad con el párrafo 3 del artículo 12".

9 Entre el 8 de julio y el 26 de aģosto de 2014 Israel ejecutó esta operación militar contra Hamás con fueģo de aviación y artillería naval y terrestre en respuesta al asesinato de tres jóvenes israelíes que fueron secuestrados cuando hacían autostop en la Cisjordania ocupada y al lanzamiento de cohetes por parte de la milicia. La incursión se saldó, según datos de la onu, con la muerte de 2251 palestinos - 1462 civiles, 551 de ellos niños - y 73 israelíes - 67 eran militares y 6 civiles - (La Vanguardia, 2016). Además, se produjeron unos 500000 desplazados internos — sobre un total de 1800000 habitantes de la Franja de Gaza, lo que siǵnifica el $\mathbf{2 7 . 7 8} \%$ del total—, de los cuales la Agencia de Naciones Unidas para los Refuģiados de Palestina en Oriente Próximo (UNRWA) refuģió en sus escuelas-refuģio a 292959 personas: 1 de cada 6 ģazatíes. La ofensiva militar israelí supuso, además, la destrucción de 17200 viviendas y que más de 100000 personas quedasen sin hogar. A todo ello hay que añadir que diversos centros de la UNRWA, coleģios-refuģios, fueron atacados, al parecer de forma deliberada - pues el goobierno de Israel conocía su emplazamiento- y sin aviso previo, por el ejército de Israel durante la ofensiva militar, lo que causó decenas de fallecimientos. También fueron atacados hospitales y ambulancias, así como médicos y personal sanitario (Human Rights Council, 2020). 


\section{Competencia de la CPI en el caso de Palestina}

Recordemos que la Fiscalía aparece como la institución clave o principal, dado que es ella, de acuerdo con el artículo 15 del Estatuto de Roma, quien puede iniciar la investigación, sobre la base de información acerca de un crimen de la competencia de la CPI. En los casos de inicio a instancia de un Estado parte o de oficio por el fiscal, de acuerdo con el artículo 12. 2, debe concurrir alguno de los supuestos mencionados en el artículo para el ejercicio de la competencia de la CPI; es decir, el Estado en cuyo territorio haya tenido lugar la conducta de que se trate o si el crimen se hubiere cometido a bordo de un buque o de una aeronave, el Estado de matrícula del buque o la aeronave o bien el Estado del que sea nacional el acusado del crimen.

En el caso concreto de Palestina, por un lado, se cumple dicha condición de competencia tras la declaración de aceptación de la competencia de la CPI de 31 de diciembre de 2014, a contar desde el 13 de junio de 2014. Por otro, la vía que está siendo utilizada es la de la Fiscalía porque, de acuerdo con el artículo 15 del estatuto, el fiscal puede iniciar de oficio una investigación sobre la base de información acerca de un crimen de la competencia de la CPI. En este sentido, surge del mencionado Documento de política general sobre exámenes preliminares: "Incumbe a la Fiscalía determinar si se cumplen los criterios estatutarios para la iniciación de investigaciones, con sujeción, cuando corresponda, a la autorización judicial".

El objetivo del examen preliminar es, conforme al artículo 53 del Estatuto, que la Fiscalía evalúe la información de que disponga y, en relación con la misma, decida si iniciará una investigación, a menos que determine que no existe fundamento razonable para proceder a ella con arreglo al estatuto. Para ello, el fiscal tendrá en cuenta si:

a) la información de que dispone constituye fundamento razonable para creer que se ha cometido o se está cometiendo un crimen de la competencia de la Corte;

b) la causa es o sería admisible de conformidad con el artículo 17;

c) existen razones sustanciales para creer que, aun teniendo en cuenta la gravedad del crimen y los intereses de las víctimas, una investigación no redundaría en interés de la justicia.

Según explica Vacas Fernández (2015), se trata de determinar, en primer lugar, si la CPI posee jurisdicción sobre los supuestos crímenes que se recogen en las informaciones que le han llegado al fiscal; en segundo, de establecer que, teniendo competencia la CPI, la situación es admisible de acuerdo con lo establecido en el 
artículo $17 .{ }^{10}$ Ello implica, en primer término, aplicar el "principio de complementariedad”, según lo establecido en los párrafos a), b) y c) del mencionado artículo; luego, valorar su gravedad de acuerdo con el párrafo d), y, en tercer lugar, sopesar el interés de la justicia en el caso. ${ }^{11}$ La relación entre la CPI y los Estados se rige por el llamado "principio de complementariedad" previsto en los artículos 1, 17, 18, 19 y 20 del Estatuto de Roma, cuyo fundamento es un sistema de soberanía compartida entre la CPI y las jurisdicciones nacionales que constituye una nueva manifestación del fenómeno de las jurisdicciones concurrentes. Conforme a este principio, la CPI constituye una jurisdicción de última ratio que solo puede activarse y posteriormente ejecutarse ante la inacción, la falta de disposición o la incapacidad de las jurisdicciones nacionales. De esta manera se consagra el principio de "primacía formal" de las jurisdicciones nacionales (Olásolo Alonso, 2009).

10 Estatuto de Roma, artículo 17. "1. La Corte teniendo en cuenta el décimo párrafo del preámbulo y el artículo 1, resolverá la inadmisibilidad de un asunto cuando: a) El asunto sea objeto de una investiģación o enjuiciamiento por un Estado que tenģa jurisdicción sobre él salvo que éste no esté dispuesto a llevar a cabo la investiģación o el enjuiciamiento o no pueda realmente hacerlo; b) El asunto haya sido objeto de investigación por un Estado que tenģa jurisdicción sobre él y éste haya decidido no incoar acción penal contra la persona de que se trate, salvo que la decisión haya obedecido a que no esté dispuesto a llevar a cabo el enjuiciamiento o no pueda realmente hacerlo; c) La persona de que se trate haya sido ya enjuiciada por la conducta a que se refiere la denuncia, y la Corte no pueda adelantar el juicio con arreģlo a lo dispuesto en el párrafo 3 del artículo 20; d) El asunto no sea de gravedad suficiente para justificar la adopción de otras medidas por la Corte".

11 Esta secuencia marca las fases en que se desarrollará la tarea de la fiscalía. Así, en la Fase l se realiza un primer análisis de la información recibida, con el objetivo de analizar si los crímenes son de competencia de la CPI o no. De este modo, todas las informaciones que lleģan a la Fiscalía se incluirán en alģuna de las siģuientes cateģorías: a) las que están manifiestamente fuera de la competencia de la cPl; b) las que se refieren a una situación que ya está bajo examen preliminar; c) las que se refieren a una situación que ya se está investigando o forma la base de un asunto que está siendo enjuiciado por la cPı, y d) las que no están manifiestamente fuera de la competencia de la cPı ni forman parte de una situación bajo examen preliminar o que ya se está investigando o enjuiciando. Las primeras serán desechadas, las segundas y terceras se añadirán al asunto correspondiente en la fase en que se encuentre y solo las del cuarto grupo pasarán a la Fase 2. En esta, se abre de manera formal el examen preliminar sobre la situación correspondiente y se centra en determinar la competencia de la cPI. La Fase 2 culmina con la presentación del fiscal de un informe sobre el artículo 5 del Estatuto de Roma - como señala el Documento de política geneneral sobre exámenes preliminares - En el caso o situación de Palestina, la Fiscalía estableció positivamente la competencia de la CPI, tanto por cumplirse en el caso, a diferencia de lo ocurrido en el 2009, las condiciones establecidas en el artículo 12, como por existir "fundamento razonable" para creer que los supuestos crímenes son competencia de la CPI. La CPI estableció las bases jurisprudenciales para definir el "fundamento razonable". En la situación República de Kenia, expresó que "fundamento razonable" es el umbral probatorio más bajo que establece el estatuto de la cPI, precisamente porque no se ha iniciado la averiģuación que provea los elementos para determinar con un grado mayor de contundencia la comprobación de los criterios establecidos en el artículo 53 de Estatuto (CPI, 2012). Respecto de la competencia, interpretó que para que exista "fundamento razonable" se requiere una justificación sensata o razonable para creer que se ha cometido o se está cometiendo un crimen de competencia de la cPI. Una vez establecida la competencia de la CPI, se pasa a la Fase 3, que se centra en la admisibilidad en términos de complementariedad y gravedad y que culmina con la elaboración de un informe sobre el párrafo 1 del artículo 53, que sirve de base para que el fiscal determine si iniciará una investigación con arreğlo al párrafo l del artículo 53 (cPı, 2009, pp. 82-83). 
En el caso que nos ocupa, sabemos que son dos los Estados implicados: Palestina e Israel. Respecto de Palestina, la declaración de reconocimiento de la jurisdicción de la CPI conlleva en sí misma una asunción de la imposibilidad de establecer por su parte responsabilidad penal en este caso. Por lo que, en relación con los presuntos autores palestinos de crímenes competencia de la CPI — que no hayan sido procesados por Israel-, la respuesta desde el análisis del principio de complementariedad que dé la Fiscalía en este caso debe ser necesariamente positiva.

La cuestión de la complementariedad, de este modo, estará centrada en Israel, Estado con un sistema judicial penal bien establecido, en funcionamiento y efectivo; por lo que no cabe hablar en su caso de incapacidad. En consecuencia, lo que la Fiscalía deberá valorar para determinar la admisibilidad o no de la Situación de Palestina de acuerdo con el principio de complementariedad es la voluntad o disposición del Estado de Israel, siguiendo los parámetros indicados. Es decir, como bien explica Olásolo Alonso (2009), lo primero que hay que determinar es si el Estado ha desarrollado o está desarrollando algún tipo de actuación en relación con los crímenes de competencia de la CPI, de tal modo que el supuesto de ausencia de procedimiento nacional - "inactividad interna"-, es suficiente para que el caso sea admisible. En caso de que el Estado en cuestión haya desarrollado investigaciones o procedimientos penales al respecto, la Fiscalía deberá proceder a analizar si tales actuaciones son "genuinas" - en el sentido de que van realmente dirigidas a establecer la responsabilidad penal sobre quienes cometieron los crímenes- o si, por el contrario, están "viciadas" - por no existir verdadera voluntad o capacidad para hacerlo-. De acuerdo con el segundo párrafo del artículo 17 del Estatuto de Roma, esta no existirá o estará viciada cuando, por ejemplo, el juicio ya haya estado o esté en marcha o que la decisión nacional haya sido adoptada con el propósito de sustraer a la persona de que se trate de su responsabilidad penal por crímenes de la competencia de la CPI, según lo dispuesto en el artículo 5, o que haya habido una demora injustificada en el juicio o que el proceso no haya sido o no esté siendo sustanciado de manera independiente o imparcial y haya sido o esté siendo sustanciado de forma en que, dadas las circunstancias, sea incompatible con la intención de hacer comparecer a la persona de que se trate ante la justicia.

Respecto a la determinación de la "incapacidad para investigar o enjuiciar", hay que atenerse a lo dispuesto en el párrafo tercero del mismo artículo. En este caso, la CPI examinará si el Estado, debido al colapso total o sustancial de su administración nacional de justicia o al hecho de que carece de ella, no puede hacer comparecer al acusado, no dispone de las pruebas y los testimonios necesarios o no está por otras razones en condiciones de llevar a cabo el juicio. 
En este punto nos parece importante destacar la noción de "complementariedad positiva", que es fijada por la Fiscalía de la CPI como objetivo intermedio o instrumental de su actuación, al indicar que, con el fin de luchar contra la impunidad - fin último de la CPI - tratará de fomentar procedimientos nacionales genuinos, alentando a los Estados para que cumplan con su responsabilidad primordial de investigar y enjuiciar los crímenes internacionales. El carácter complementario de la CPI requiere que las autoridades judiciales nacionales y la CPI funcionen conjuntamente. En palabras de Olásolo Alonso (2009):

el examen se erige así en un instrumento para que se promueva el fortalecimiento del estado de derecho y de los organismos jurisdiccionales nacionales a los efectos de que pueden ser estos últimos los que desarrollen las investigaciones y enjuiciamientos de los delitos de competencia de la CPI cometidos en su territorio o por sus nacionales (p. 91).

\subsection{La CPI y la "Situación de Palestina". La decisión de la Fiscal de iniciar la investigación del 20 de diciembre de 2019}

El viernes 20 de diciembre de 2019, la fiscal de la CPI anunció su decisión de iniciar una investigación sobre la "Situación de Palestina". La decisión hace referencia a todas las acciones tomadas en Cisjordania, Jerusalén del Este y la Franja de Gaza desde el 13 de junio de 2014, sosteniendo que hay una base razonable para creer que crímenes de guerra fueron cometidos por las Fuerzas de Defensa israelíes, así como por Hamás y otros grupos armados palestinos (Urgente24, 2020; Aurora, s. f.).

Este anunció marcó el fin del examen preliminar que comenzó en enero de 2015. Sin embargo, junto con su fallo, la fiscal solicitó que la división de cuestiones preliminares dictaminase sobre el alcance de la jurisdicción territorial en este caso. $\mathrm{Al}$ respecto, la fiscal observó que, aunque no existe un requisito para que la División de Cuestiones Preliminares autorice el inicio de una investigación, dado que se realizó un examen de conformidad con una referencia explícita de un Estado involucrado (Palestina), solicita la opinión de la cámara frente al alcance de la jurisdicción territorial de la CPI en la situación en Palestina. Específicamente, busca la confirmación de que el "territorio" sobre el cual la CPI puede ejercer su jurisdicción comprende el "Territorio Palestino Ocupado": Cisjordania, incluida Jerusalén Oriental, y la Franja de Gaza.

Son importantes los argumentos que da la fiscal por los que cree que Palestina puede ser vista como un Estado a los efectos de la jurisdicción de la CPI. Primero, afirma que la aceptación de la Asamblea General de la onu de Palestina como 
"Estado Observador No Miembro" es suficiente para ese fin. Más allá de este argumento formal, ofrece una revisión detallada de la afirmación alternativa de que Palestina también cumple con las condiciones sustantivas requeridas para la condición de Estado según el derecho internacional. Argumenta, que a pesar de que Palestina no ejerce control total sobre todo el territorio de Cisjordania y Jerusalén del Este - que está bajo control israelí- y la Franja de Gaza - que está bajo el gobierno de Hamás-, debe ser reconocido como un Estado en la totalidad del territorio por tres motivos: primero, dado el reconocido del derecho del pueblo palestino a la libre autodeterminación en el "Territorio Palestino Ocupado"; segundo, dado el impacto perjudicial de las continuas violaciones de Israel del derecho internacional en la construcción de los asentamientos y la valla de seguridad, que impiden la realización de este derecho a la autodeterminación, y tercero, dado que 135 Estados han reconocido al Estado de Palestina.

La fiscal subraya, además, que tratar a Palestina como un Estado es coherente con el objeto y el propósito del Estatuto de Roma de evitar que los criminales de guerra escapen de la justicia, ya que Israel considera que los asentamientos son legales, y que la Corte Suprema, a pesar de su reconocida independencia, dictaminó el asunto "no justiciable". La fiscal afirma que las limitaciones a la jurisdicción penal de la ANP, según lo establecido en el Acuerdo Provisional, no afectan la posible jurisdicción de la CPI para discutir todos y cada uno de los delitos cometidos en el territorio de Palestina. Además, la falta de control de la ANP sobre Gaza y la incertidumbre con respecto a las fronteras finales de Palestina, no afectan la jurisdicción para discutir crímenes en el territorio que se considera pertenecen a este Estado, incluso si finalmente hay cambios en la frontera como resultado del intercambio de territorios con Israel.

En relación con los posibles crímenes de guerra durante la "Operación Margen Protector" (julio-agosto 2014), la fiscal, quien destacó la independencia de los tribunales israelíes, dejó una apertura para la aceptación del argumento de que, bajo el ya mencionado "principio de complementariedad", estos incidentes no están dentro de la jurisdicción de la CPI si Israel conduce investigaciones genuinas sobre el asunto, probando que tiene una justicia militar confiable. Es decir, y tal como hemos visto anteriormente, la CPI solo puede tomar acción como último recurso en instancias en las que no hay un sistema de justicia creíble que pueda hacerse cargo de las acusaciones relativas a crímenes de guerra.

En otra parte de la argumentación, se apunta a que Israel podría estar cometiendo un crimen de guerra al promover la construcción de asentamientos en Cisjordania; esto, en virtud de que para el Estatuto de Roma (artículo 8), es un crimen de guerra 
[el] traslado, directa o indirectamente, por la Potencia ocupante de parte de su población civil al territorio que ocupa o la deportación o el traslado de la totalidad o parte de la población del territorio ocupado, dentro o fuera de este territorio.

Dado que Israel y sus cortes no los ven como un delito de ese tipo, será difícil para Israel argumentar que su sistema legal puede investigar el asunto, por lo que en este punto sí puede intervenir la CPI.

\section{Conclusiones}

De lo expuesto a lo largo de estas páginas, no cabe duda alguna de que Palestina es un pueblo con derecho a que se respete su libre autodeterminación y, a su vez, con determinación a través de la historia para forjar su identidad nacional pese a la ocupación y a los proyectos extranjeros. Dicha determinación en los últimos años le valió el reconocimiento como Estado de la mayor parte de la comunidad internacional.

Palestina, además, ha mostrado reafirmar la búsqueda de la paz como opción estratégica, lo que se tradujo en la realización de negociaciones con Israel — desde ya, infructuosas- a fin de alcanzar ese objetivo, de acuerdo con los principios y fundamentos de la legitimidad internacional, exigiendo básicamente, la retirada total de Israel de todos los territorios árabes ocupados, el ejercicio de los derechos inalienables del pueblo palestino, en particular, su derecho a la libre autodeterminación y al establecimiento de un Estado independiente con Jerusalén como capital. En este contexto, la política exterior de Palestina se ha enmarcado en criterios como el compromiso con la Carta de las Naciones Unidas, los objetivos y las normas del derecho internacional y la Declaración Universal de Derechos Humanos, estableciendo buenas relaciones con todos los países sobre la base de la igualdad y el respeto mutuo. No obstante, reclama a la onu la efectiva aplicación de sus numerosas resoluciones como requisito para el logro de una paz justa y duradera en la región, medida unilateral que Israel no está - ni estuvo nunca - dispuesta a aceptar. ${ }^{12}$

La CPI consideró en la revisión preliminar que, en vista de que "se han cometido o se están cometiendo crímenes de guerra" por parte de las Fuerzas de Defensa de Israel y del grupo armado palestino Hamás, las investigaciones en estos lugares son "con base razonable". En cuanto a los primeros, la oficina cree que atacaron de manera deliberada y desproporcionada a civiles y personal de salud. También

12 Por el contrario, Israel postula una solución bilateral del conflicto, con Estados Unidos como mediador, como el recientemente propuesto Plan de paz para medio Oriente, por parte del expresidente de los Estados Unidos, Donald Trump, que deja los asentamientos en territorio palestino bajo control israelí, respalda la anexión por parte de Israel del Valle del Jordán y propone la creación de un Estado palestino bajo estrictas condiciones (Páginal2, 2020). 
insistió en que los últimos dispararon misiles contra Israel de forma indiscriminada durante la guerra de 2014.

Bensouda declaró en febrero de 2021 que no necesitaba obtener autorización de una de las salas de la CPI para realizar investigaciones en estos territorios, debido a que Palestina se adhirió al Estatuto de Roma desde 2015 y por lo tanto reconoció la competencia de la CPI para investigar delitos y crímenes. No obstante, la tensión es que la investigación se llevará a cabo en los territorios ocupados por Israel, que aún no se han adherido a la CPI.

Del otro lado, Israel continuó con su política de asentamientos en los territorios palestinos ocupados, así como con el bloqueo en la Franja de Gaza y Cisjordania, territorios en los que sobreviven alrededor de 1.4 millones de personas en condiciones sumamente precarias, lo que crea, a su vez, una crisis humanitaria por el bloqueo debido a los altos niveles de pobreza y carencia de elementos básicos para una vida digna. A esto se le suman los ataques perpetrados por las fuerzas militares israelíes que involucran a la población civil y la construcción de un muro que abarca en su mayor parte la ribera occidental - al que se ha llamado "valla de seguridad"-, pero que en realidad constituye una indebida partición y aislamiento de comunidades enteras. En este sentido, y en relación con los demás Estados que conforman la comunidad internacional, la cij en su opinión consultiva del 2004, determinó que entre las obligaciones violadas por Israel hay algunas erga omnes, como el derecho del pueblo palestino a la libre determinación, así como ciertas obligaciones bajo el derecho internacional humanitario, las cuales deben ser observadas por todos los Estados debido a que constituyen principios intransgredibles de derecho internacional consuetudinario. Por lo tanto, para la CIJ, todos los Estados tienen la obligación de no reconocer la situación ilegal resultante de la construcción de un muro en el territorio palestino ocupado.

Desde el punto de vista del derecho internacional, entonces, Israel no ha hecho más que demostrar un desprecio hacia el mismo. Como dice Escudero Alday (2009):

Un desprecio que se observa desde hace ya demasiados años en dos grandes ámbitos temáticos y de actuación (...) En primer término, en las cuestiones relativas al llamado "estatuto final", nombre utilizado para englobar los puntos centrales de conflicto sobre los que el derecho internacional ya se ha pronunciado. $Y$, en segundo término, en las continuas y flagrantes violaciones por parte del Estado de Israel de las obligaciones que le incumben en virtud del derecho internacional de los derechos humanos (p. 306). 
A su vez, si bien Israel ratificó el Cuarto Convenio de Ginebra en 1951, rechaza su aplicación a los territorios palestinos ocupados basándose en diversos criterios. El no reconocimiento por parte de Israel del carácter de derecho consuetudinario del convenio es un medio para eludir sus obligaciones para instrumentarlo, mientras que su disposición para aceptar las "disposiciones humanitarias" de dicho instrumento internacional ha demostrado ser una promesa incumplida a la luz de las políticas y acciones implementadas a lo largo de los años.

Consecuentemente, Israel rechaza de plano la intervención de la CPI en el conflicto que mantiene con Palestina, argumentando que esta no tiene jurisdicción sobre los territorios ocupados, ya que aplica solo a los Estados soberanos y para Israel, nunca hubo un Estado palestino. Del mismo modo que ha procedido a eludir la aplicación de otros instrumentos internacionales, Israel ha firmado el Tratado de Roma, pero no lo ha ratificado, en una clara intención de sustraerse a su competencia. Por lo tanto, reniega también del derecho penal internacional y, en consecuencia, no creemos que este país vaya a prestar algún tipo de colaboración con la investigación llevada a cabo en el marco del Estatuto de Roma, y menos, proceder a la ratificación de este, aun guiado por la presión internacional respecto del caso. Pese a ello, y tal como desde el punto de vista del derecho penal internacional hemos analizado, en virtud del principio de complementariedad, cabe la posibilidad de que respecto de algunas acusaciones - concretamente sobre los asentamientos ilegales-, la CPI tenga jurisdicción para investigar a Israel.

En nuestra opinión, si bien se sostiene que esta jugada de la ANP puede llevar a un empeoramiento en las relaciones de ambas partes, creemos que enmarcar este conflicto en la jurisdicción de la CPI — y en un escenario ideal— hará que soldados israelíes operando en Gaza y Cisjordania, como así también, militantes terroristas de Hamás, estén bajo su supervisión. Esto podría, por un lado, incentivar a que Israel adecúe sus políticas antiterroristas a los estándares que le reclama la comunidad internacional y por otro, que este país y Al-Fatah (la organización político-militar palestina fundada en 1958 en Kuwait, por Yasser Arafat) puedan trabajar juntos para hacer cumplir las órdenes de arresto de todos los acusados a fin de que puedan ser sentenciados en La Haya. Apostamos, entonces, a que la justicia y la paz, en este caso, puedan ir de la mano. 


\section{Referencias}

Asamblea General, Organización de las Naciones Unidas. (14 de diciembre, 1960). Declaraación sobre la concesión de la independencia a los países y pueblo coloniales. https://www.ohchr.org/SP/ProfessionalInterest/Pages/Independence.aspx

Asamblea General, Organización de las Naciones Unidas. (24 de octubre, 1970). Declaración sobre los principios de derecho internacional referentes a las relaciones de amistad y a la cooperación entre los Estados de conformidad con la Carta de las Naciones Unidas. A/RES/2625(XXV). https://www.undocs.org/ pdf?symbol=es/A/RES/2625(XXV)

Asamblea General, Organización de las Naciones Unidas. (6 de diciembre, 1971). Importancia de la realización universal del derecho de los pueblos a la libre determinación y de la rápida concesión de la independencia a los países y pueblos coloniales para la efectiva garantía y observancia de los derechos humanos. A/RES/2787(XXVI). https://www.dipublico.org/4026/resolucion-2787-xxvi-de-la-asamblea-general-importancia-de-la-realizacion-uni\%C2\%ADversal-del-derecho-de-los-pueblos-a-la-libre-determinacion-y-de-la-rapida-concesion-de-la-independencia-a-los-pais/

Asamblea General, Organización de las Naciones Unidas. (22 de noviembre, 1974). Cuestión de Palestina. A/RES/3236(XXIX). https://undocs.org/pdf?symbol=es/A/RES/3236(XXIX)

Asamblea General, Organización de las Naciones Unidas. (2004). Medidas ilegales israelíes en la Jerusalén oriental ocupada y el resto del territorio palestino ocupado. Opinión Consultiva de la Corte Internacional de Justicia sobre las consecuencias jurídicas de la construcción de un muro en el territorio palestino ocupado. A/ES-10/273. https://www.icj-cij.org/public/files/advisory-opinions/advisory-opinions-2004-es.pdf

Asamblea General, Organización de las Naciones Unidas. (2019). Resolución aprobada por el Consejo de Derechos Humanos el 22 de marzo de 2019. A/HRC/ RES/40/22. https://undocs.org/pdf?symbol=es/A/HRC/RES/40/22

Ash, R. W. (2009). Is Palestine a 'state'? A response to Professor John Quigley's article. 'The Palestine declaration to the International Criminal Court: The statehood issue.' Rutgers Law Record, 36, 186-200. https://awrecord.com/ files/36_Rutgers_L_Rec_186.pdf 
Aurora. (s. f.). La Corte Penal Internacional sobre Israel: otro paso hacia la investigación. https://aurora-israel.co.il/la-corte-penal-internacional-sobre-israel-otro-paso-hacia-la-investigacion/

Comité de Derechos Humanos, Organización de las Naciones Unidas. (2020). The United Nations independent commission of inquiry on the 2014 Gaza conflict. https://www.ohchr.org/en/hrbodies/hrc/coigazaconflict/pages/reportcoigaza.aspx

Comité de Derechos Humanos, Organización de las Naciones Unidas. (2019). Human rights situation in Palestine and other occupied Arab territories. Report of the independent international commission of inquiry on the protests in the Occupied Palestinian Territory. A/HRC/40/74. https://digitallibrary.un.org/ record $/ 3801176 ? \ln =$ es

CNN en español. (17 de enero de 2015). La Corte Penal Internacional Investiga si Israel cometió crímenes de guerra en Palestina. CNN en español. https:// cnnespanol.cnn.com/2015/01/17/la-corte-penal-internacional-investiga-si-israel-cometio-crimenes-de-guerra-en-palestina/

Consejo de Seguridad, Organización de las Naciones Unidas. Resolución 2334(2016) (23 diciembre 2016). S/RES/2334. https://www.dipublico.org/104780/resolucion-2334-2016-consejo-de-seguridad-de-las-naciones-unidas-sres2334/

Corte Penal Internacional. (1998). Estatuto de Roma. https://www.un.org/spanish/ law/icc/statute/spanish/rome_statute(s).pdf

Escudero Alday, R. (2009). Israel, democracia y derecho internacional. Nombres Revista de Filosofía, (23), 305-331. https://revistas.unc.edu.ar/index.php/ NOMBRES/article/view/2501

Dreifus, M. (20 de diciembre de 2019). Israel condena la decisión de La Haya. Y Net Español. https://www.ynetespanol.com/global/israel/article/r100BgDc0S

Guimón, P. (11 de septiembre de 2018). ee. uu. arremete contra el tribunal de La Haya y amenaza con sancionar a sus jueces. El País. https://elpais.com/internacional/2018/09/10/estados_unidos/1536602005_815622.html

La Vanguardia. (26 de agosto de 2016). Se cumplen 2 años de la operación "Margen Protector" con más de 2300 muertos. La Vanguardia. https://www.lavanguardia.com/internacional/20160826/404206796024/se-cumplen-2-anos-de-la-operacion-margen-protector-con-mas-de-2300-muertos.html 
La Vanguardia. (20 de diciembre de 2019). La Corte Penal Internacional investigará a Israel por presuntos "crímenes de guerra" en Palestina. La Vanguardia. https:// www.lavanguardia.com/internacional/20191220/472370940070/corte-penal-internacional-investigara-israel-crimenes-guerra-palestina.html

México, Comisión Nacional de Derechos Humanos. Acuerdo sobre los privilegios e inmunidades de la Corte Penal Internacional (26 de octubre de 2007). https:// www.cndh.org.mx/DocTR/2016/JUR/A70/01/JUR-20170331-II98.pdf

Oficina del Fiscal, Corte Penal Internacional. (2013). Documento de política general sobre exámenes preliminares. https://www.icc-cpi.int/iccdocs/otp/OTP-Policy-Paper-on-Preliminary-Examinations--November2013-SPA.pdf

Oficina del Fiscal, Corte Penal Internacional. (2019). Report on preliminary examination activities (2019). https://www.icc-cpi.int/itemsDocuments/191205-rep-otp-PE.pdf

Olásolo Alonso, H. (2009). Ensayos sobre la Corte Penal Internacional. Pontificia Universidad Javeriana - Biblioteca Jurídica Diké.

Organización de las Naciones Unidas. (1992). Resúmenes de los fallos, opiniones consultivas y providencias de la Corte Internacional de Justicia. ST/LEG/SER.F/1. https://legal.un.org/icjsummaries/documents/spanish/st_leg_serf1.pdf

Sala de Apelaciones, Corte Penal Internacional. (2011). Situación en la república de Kenya en la causa de El Fiscal c. William Samoei Ruto, Henry Kiprono Kosgey y Joshua Arap Sang. ICC-01/09-01/11 OA. https://www.icc-cpi.int/ CourtRecords/CR2012_02708.PDF

Urgente 24. (21 de enero, 2020). La batalla que se viene entre Israel y la Corte Penal Internacional. Urgente 24. https://urgente24.com/medios/exclusivo-24/ la-batalla-que-se-viene-entre-israel-y-la-corte-penal-internacional

Página 12. (29 de enero de 2020). Trump ideó un plan de paz a la medida de Israel. Página 12. https://www.pagina12.com.ar/244380-trump-ideo-un-plan-de-paz-a-la-medida-de-israel

Vacas Fernàndez, F. (2015). El reconocimiento de la jurisdicción y la ratificación del Estatuto de la Corte Penal Internacional por el Estado de Palestina: un proceso complejo con importantes consecuencias jurídicas. Revista Electrónica de Estudios Internacionales, (30), 1-43. https://doi.org/10.17103/reei.30.12 